\title{
Editorial
}

\section{Impact of COVID-19 on general surgical residents in a tertiary care centre in India}

\author{
Divya Dahiya*, Kishore Abuji, Akhilesh Kumar Yadav, \\ Cherring Tandup, Arunanshu Behera
}

\begin{abstract}
Department of General Surgery and Department of Psychiatry, Post Graduate Institute of Medical Education and Research, Chandigarh, India
\end{abstract}

Received: 14 March 2021

Accepted: 16 April 2021

*Correspondence:

Dr. Divya Dahiya,

E-mail: dahiyadivya30@gmail.com

Copyright: (C) the author(s), publisher and licensee Medip Academy. This is an open-access article distributed under the terms of the Creative Commons Attribution Non-Commercial License, which permits unrestricted non-commercial

COVID-19 was declared as a public health emergency of international interest on 30 January 2020; and as a pandemic on 11 March $2020 .{ }^{1}$ In order to minimise the spread and to optimize the health care resources Indian government announced national lock down with suspension of all routine hospital activities (outpatient clinics, routine surgeries) on March 24, 2020. Only emergency services were allowed along with diversion of all available resources to COVID centre.

In this period of national emergency because of COVID19, there was a change in surgical practice and boundaries were pushed to replace an old system to a new system to provide the best both to the patients and the residents. All routine outpatient clinics were stopped. Only emergency surgical care and urgent cases requiring surgeries for malignant or benign diseases were continued. All patients who were planned for either emergency or elective surgical procedures were tested for COVID-19 by RT-PCR before admitting to surgical ward and before going to operating room. This practice significantly reduced the number of cases assisted and operated by the residents. Residents were posted on-call ward duties, emergency duties, outpatient clinics for oncology cases and COVID duty. Teleconsultation was started to assist health system and to reduce the number of patients visiting the hospital. All regular teaching schedules was disrupted and all scheduled clinical case discussions, journal club, grand round, bed side classes were organised online to minimize exposure and spread among the staff.
This new way of working completely changed the functioning of general surgery department. The graded training of preoperative and postoperative management of surgical patients along with the hands-on experience for the development of technical skills is the most important aspect for a surgical resident. The prime concern of continuing improvement of clinical and practical skills of residents was weighed down.

Another major concern for surgical residents was to work in emergency department where each patient is a suspect of harbouring COVID-19 infection and also to operate upon COVID-19 positive patients using personal protective equipment (PPE). Use of PPE is not easy as more than $40 \%$ of medical staff treating COVID-19 infected patients may experience serious skin injury secondary to use of masks, goggles, face shields, and protective gowns. $^{2-4}$ Also, it is difficult to operate for long hours using PPE. It is suffocating, it decreases the vision because of fogging, tactile sensations are reduced and also intensive work for long hours put residents at risk of mental stress, and fear of getting infected. Therefore, we conducted an online Google survey with 24 questions and circulated it among general surgical residents with the aim to evaluate the effect of COVID-19 pandemic on surgical training from residents' point of view. It was circulated among 86 junior and 19 senior residents in the department of general surgery. There were total of 85 male and 19 female residents; 89 of those were single and 15 were married and were staying with their family. Majority $(\mathrm{N}=49,47.1 \%)$ reported no change in duty hours, $31(29.8 \%)$ reported increase in duty hours as 
these residents were posted in emergency ward; however $24(23 \%)$ residents reported decrease in work load as they were posted in ward where only COVID-19 negative elective patients with malignancy were admitted. Rearrangement of residents mainly to one place, i.e. emergency services hampers their methodical surgical training in all fields. Majority $(\mathrm{N}=72,69.2 \%)$ considered that there is loss of crucial months in their training. Only $26(25 \%)$ residents think that this loss can be recovered in future. In terms of impact of pandemic on their surgical career, 90 residents believe that it will have a major influence in future.

Majority of residents ( $\mathrm{N}=74,73.07 \%)$ reported decrease in operating room work both as an assistant and as an operating surgeon. The operating loss was realised mainly by junior residents as operating procedures in emergency in our institute are performed by senior residents. This reduction in the practical activity was because of near complete cessation of elective admissions and surgeries. Only malignancy and urgent cases were performed in routine operating room by senior surgeons; surgeries for hernia, laparoscopic cholecystectomy, procedures for varicose veins etc were not performed which are usually done by the residents under supervision in elective operating room. Elective malignancy cases were operated by faculty to decrease the operative time and utilise the maximum of operation theatre services.

Eighty six of the residents were afraid of being infected themselves; and 94 were afraid to infect their colleagues and family members. One third of the residents were proud of working in COVID ward; however 40 residents felt hectic and 21 were depressed working and taking care of COVID patients. Twelve residents thought of discontinuing their residency. Experience of using PPE was also scary as majority found difficult to perform surgeries (69.2\%) and had increased stress (61.5\%). Dehydration was experienced by $67.3 \%$, profuse sweating by $60.5 \%$, fogging by $67.3 \%$, headache $57.6 \%$, difficulty in breathing $59.6 \%$ and fatigue by $50 \%$. One third of residents also experienced myalgia and skin irritation with prolonged use of PPE. Teleconsultation for patients was started and majority felt it is like working in a call centre; only 2 felt it is of any use to them; however
42 residents thought it may be of some benefit to the patient. Webinars to facilitate teaching in the form of case discussion, journal club and topic discussions were conducted and 94 residents still felt that academics were affected. However, we think that such virtual learning on selective basis may be useful in future to prevent burnout and allow time to focus on learning technical skills.

To conclude, this COVID-19 pandemic has dent the ongoing surgical teaching significantly by omitting the clinical and hands on training for surgical residents. Even if webinars are being conducted regularly to provide virtual experience about patients problems along with case discussions, other alternative ways and implementation methodologies are required to be developed for compensating upon such vital deficits in future.

\section{REFERENCES}

1. Borges do Nascimento IJ, Cacic N, Abdulazeem HM, von Groote TC, Jayarajah U, Weerasekara I, et al. Novel coronavirus infection (COVID-19) in humans: a scoping review and meta-analysis. J Clin Med. 2020;9(4):941.

2. Jiang Q, Song S, Zhou J, Liu Y, Chen A, Bai Y, et al. The prevalence, characteristics and prevention status of skin injury caused by personal protective equipment among medical staff in fighting COVID19: A multicenter, cross-sectional study. Adv Wound Care. 2020;9:357-64.

3. Hu K, Fan J, Li X, Gou X, Li X, Zhou X. The adverse skin reactions of health care workers using personal protective equipment for COVID-19. Medicine. 2020;99:24.

4. Lim ECH, Seet RCS, Lee KH, Wilder-Smith EPV, Chuah BYS, Ong BKC. Headaches and the N95 face-mask amongst healthcare providers. Acta Neurol Scan. 2006;113: 199-202.

Cite this article as: Dahiya D, Abuji K, Yadav AK, Tandup C, Behera A. Impact of COVID-19 on general surgical residents in a tertiary care centre in India. Int Surg J 2021;8:1965-6. 